\title{
Scabies in Edinburgh from 1815 to 2000
}

\author{
J A Savin MD FRCP
}

J R Soc Med 2005;98:124-129

The Royal Infirmary of Edinburgh (RIE) was founded in 1729. Since then it has moved three times, in 1741,1880 and 2002. During the last move dermatology records thought to have been destroyed in $1936^{1}$ were found. They go back to 1906 and lie at the heart of this paper. Their discovery triggered an analysis of other Edinburgh health records, from which details of large numbers of patients with skin infections and infestations, including nearly 16000 with scabies, have been harvested. A complex picture emerges of their interacting epidemiology in Edinburgh over a period of nearly two centuries through the 'sanitary awakening' of the nineteenth century to the present day.

\section{INFORMATION SOURCES AND METHODS}

The Dermatology Department at the RIE was founded in 1884. ${ }^{2}$ An accurate diagnostic index ${ }^{3}$ ran from 1906 until 1958. Thereafter clinic books recorded the same information in undigested form until 1969. A computerized diagnostic index then took over, but shed its contents in the 1970s. Most recently, a series of snapshot studies of the workload of the department has covered the years from 1981 to $2000 .{ }^{4-6}$

The Edinburgh Dispensary for Diseases of the Skin (EDDS) was founded in 1890 to give free treatment to those who could not pay for it. The number of patients seen there slumped after the National Health Service took up the same role in 1948, and the dispensary closed in 1963. Its annual reports, from 1896 to 1963 , record the patients seen there over that time.

In the late eighteenth century, the Old Town of Edinburgh spilled over from its volcanic crag-and-tail perch, and flowed northwards. The Edinburgh New Town Dispensary was set up in 1815 to help those who could not afford medical treatment. In essence it was an early type of general practice. Details of the patients seen are available only for the years 1815 to $1819 .{ }^{7}$

The figures for the Skin Clinic for Edinburgh School Children are known only for the years 1938 to $1940 .{ }^{8}$

The number of new patients of all types seen at Edinburgh's skin clinics and dispensaries increased over the period covered by this study. At the RIE skin clinic, for instance, there was a threefold increase from 1926 to 1962.

St Ann's, 12 York Road, North Berwick EH39 4LX, Scotland, UK
Any increase in the number of patients seen with scabies might simply have been part of this general change, and so the figures for scabies and other skin diseases are presented here as percentages of all new patients seen. To help the reader, some comments are interpolated in the section on findings.

\section{FINDINGS}

The proportion of new patients seen at both the RIE skin clinics and the EDDS with skin infestations and infectionsthe so-called dermatoses of poverty - fell dramatically during the twentieth century (Figure 1). Viral warts are not included in these figures.

In the first half of the nineteenth century, factories sucked the population of Britain into the towns. Living conditions soon became appalling and at that time Edinburgh was one of the dirtiest cities in Europe. It was a place for 'high thinking but also high stinking'. Its 'stercoraceous' smell was so offensive that those who

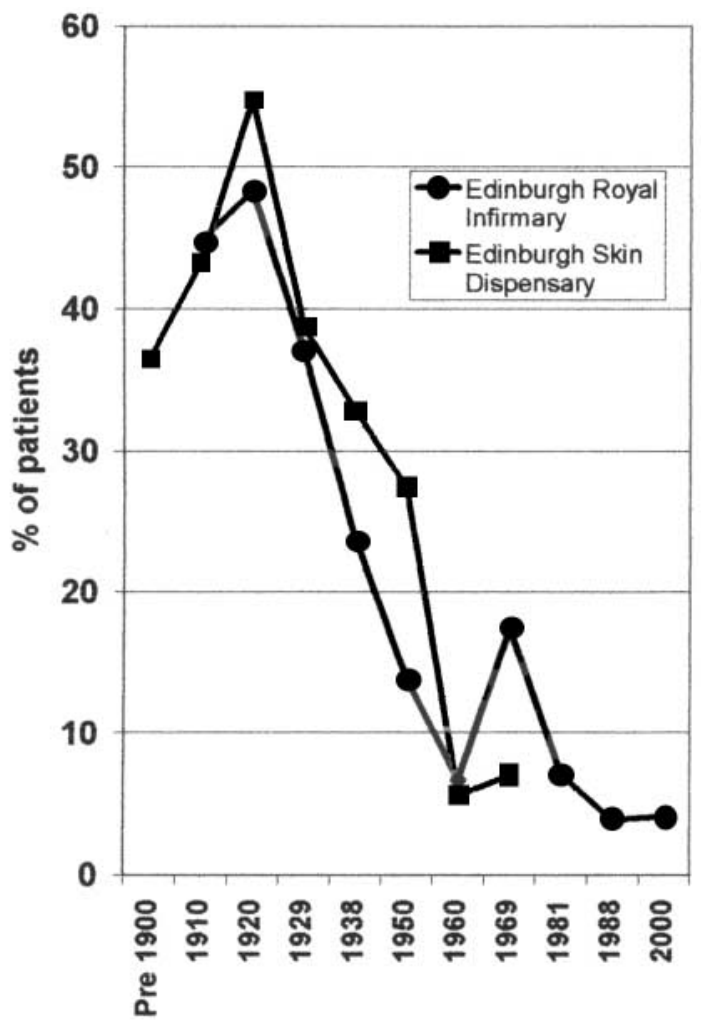

Years from 1896 to 2000

Figure 1 Infections and infestations as percentage of new patients seen 
Table 1 New patients with scabies: numbers, and the percentage they made up of all new skin patients

\begin{tabular}{llccc}
\hline Years & Institution & $\begin{array}{l}\text { So. of patients } \\
\text { with scabies }\end{array}$ & $\begin{array}{l}\text { Sotal No. of patients patients } \\
\text { as \% of all patients } \\
\text { with skin disease }\end{array}$ \\
\hline $1815-1819$ & Edinburgh New Town Dispease & & 30.2 \\
$1896-1963$ & Edinburgh Dispensary for Diseases of the Skin & 3471 & 3124 & 9.7 \\
$1908-1969$ & Royal Infirmary Skin Clinic & 9917 & 35924 & 3.6 \\
$1938-1940$ & Skin Clinic for Edinburgh School Children & 1597 & 273605 & 33 \\
Overall & & 15930 & 318524 & 5.0 \\
\hline
\end{tabular}

walked through its streets had to hold their noses. Perhaps as a result, in 1862 Edinburgh was the first Scottish local authority to appoint its own medical officer of health. For the next 46 years the dynamic Dr Henry Littlejohn attacked the sickening chaos of squalid living in the slums with the aid of his 'medical police' and later with the powers given to him under the Public Health (Scotland) Act of 1867. When he retired in 1908, cholera and typhus had left Edinburgh and smallpox was no longer a serious threat. Sanitation had improved, real income had increased, and food was more easily available. The population per acre fell from 49.0 in 1863 , to 28.1 in 1913 , and 13.9 in 1958. Deaths from infectious diseases fell from 6.23 per thousand in 1863 to 0.87 in 1913 and 0.03 in $1958 .{ }^{9}$ Skin morbidity fell in parallel with mortality during the general sanitary awakening of the twentieth century.

\section{Scabies}

Table 1 shows the number of patients with scabies included in this study, and the percentage they made up of all new patients.

\section{Edinburgh New Town Dispensary}

21509 new patients were seen by the staff of the dispensary between its founding in September 1815 and the end of June 1819. Of these, $3124(14.5 \%)$ had a skin disorder. The 945 patients with scabies made up $30.2 \%$ of the patients with skin conditions and $4.4 \%$ of all patients. ${ }^{7}$

The New Town Dispensary patients were seen just after the Napoleonic Wars, during which sufferers from scabies in the French army could be counted by the hundred thousand. ${ }^{10}$ The Prussian army was infested too, and after the war the disease spread far and wide. ${ }^{11}$ The Edinburgh manifestation of this may have been the mass of patients with scabies who swarmed into the New Town Dispensary between 1815 and 1819 .

\section{Royal Infirmary of Edinburgh}

\section{Percentage of new patients with scabies}

Figure 2 shows the percentage of new patients with scabies seen at the skin clinic of the RIE from 1908 to 1969 , and at the EDDS from 1896 to 1963 . At both clinics the figures peaked during the two World Wars (1914-1918, 19391945) with low levels persisting thereafter.

Epidemics of scabies are often said to be cyclical, but the intervals reported between them have ranged from 7 to 30 years. In addition, most studies have dealt with only two epidemics, without establishing that a third one appeared after the predicted interval.

In Edinburgh, one epidemic of scabies began in 1914 and another in 1939, 25 years later. The minor increases in the 1960s and 1980s were not comparable to these. In Denmark, similarly, the figures for scabies between 1900 and $1970^{12}$ showed only two main peaks, coinciding with the World Wars. The incidence of scabies clearly fluctuates but this may not truly be cyclical. ${ }^{13}$

Wars coincide with high levels of scabies. The evidence for this is strong, ${ }^{13}$ and steep rises in scabies were seen at two unconnected skin clinics in Edinburgh during both the World Wars. However, scabies is not unique in this respect; many other contagious diseases 'burst into full flame' during wartime. Sexually transmitted diseases in the UK rose during both World Wars, ${ }^{14}$ as did deaths from meningococcal meningitis and respiratory diseases.

Debate over the roles of wars and 'herd immunity' in epidemics of scabies has become too polarized. Both fit into the same general scheme. Wars, and the social disruption they cause, predispose to overcrowding, poor hygiene and population movement, and therefore will increase the number of encounters between susceptible and infested individuals. However, no epidemic will follow if true herd immunity exists and the number of susceptibles remains below the threshold level. In scabies the herd immunity theory of epidemics is weakened by the facts that 


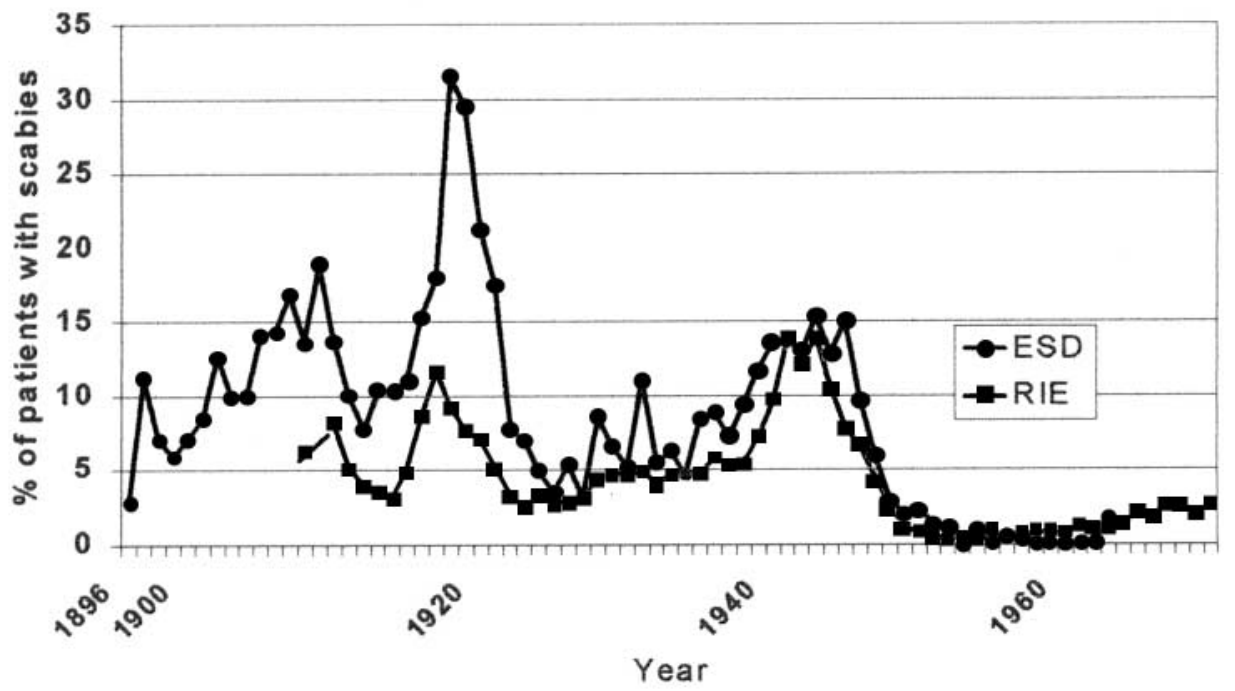

Figure 2 Scabies in Edinburgh: 1896-1970 (Royal Infirmary of Edinburgh and Edinburgh Dispensary for Diseases of the Skin figures)

reinfestation is common and that high levels of scabies are endemic in some areas.

This study sheds light on both aspects of scabies epidemiology. The two epidemics of scabies in Edinburgh coincided precisely with the World Wars, starting when they started and falling over a few years once they had stopped. Soldiers bringing scabies home with them were probably responsible for its spread in Edinburgh during and after the World Wars. During the First World War threequarters of the skin cases in one military base hospital had conditions that were 'frankly scabetic or secondary to scabies', 15 and in Edinburgh at the same time it was thought 'remarkable in how many instances patients could attribute the disease to infection from some soldier member of the family' ${ }^{16}$ Scabies rose in London too, as shown by the sharp increase in 1915 in the number of cases treated in the cleansing stations of the London County Council. ${ }^{17}$ Scabies became common in neutral European countries at the same time. ${ }^{13}$

\section{Gender and age at presentation}

At the RIE, males seen with scabies outnumbered females before 1928: after 1937, females outnumbered males. The age at which infested males and females presented to the RIE skin clinic also differs. The combined figures for the years 1931, 1935, 1939, 1943, and 1947 are shown in Figure 3. In males, the peak age at presentation was between 0 and 10 years: in females it lay between 11 and 20. The mean and median ages of male and female patients presenting to the skin clinic between 1935 and 1947 are shown in Figure 4. The lowest were in 1939, at the start of the epidemic. A higher proportion of the males presenting with scabies during 1939 and 1943 (i.e. at the start of and

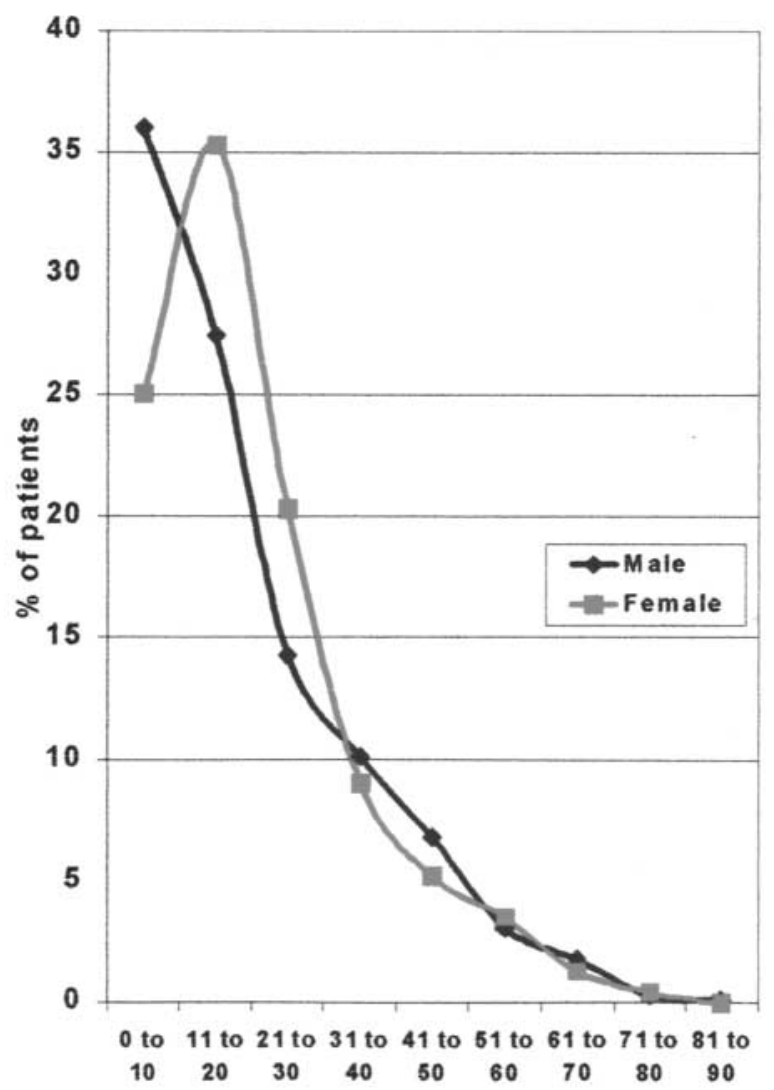

Figure 3 Scabies patients seen at the Royal Infirmary in 1931, 1935, 1939, 1943 and 1947: 711 male and 983 females. Patients by age at presentation

fit the idea that changes in herd immunity played a part in the epidemic, with a new generation of non-immune individuals, born since the previous epidemic, becoming infested.

There is little difference worldwide between the incidence of scabies in males and females. In the present 


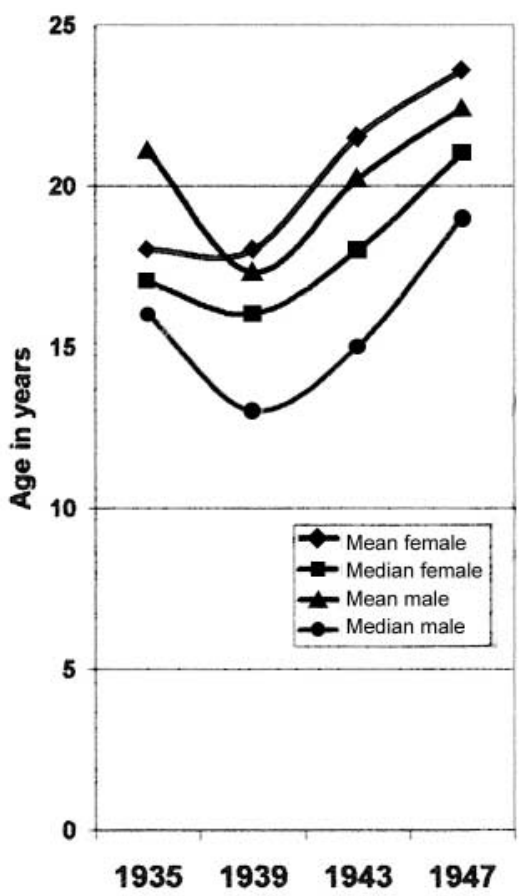

Figure 4 Scabies patients seen at the Royal Infirmary of Edinburgh in 1935, 1939, 1943 and 1947: mean and median ages at presentation

study the excess of infested females seen after 1937 may have reflected the exit of males to serve in the Armed Forces. When the World Wars began, the proportion of susceptibles in the population must have been over the required threshold for an epidemic to start.

\section{Seasonality}

Scabies sufferers made up a higher proportion of the new skin cases seen at the RIE during the cold months than in the warm months. This was obvious both during the epidemic of scabies from 1941 to 1945 and when there was no such epidemic (from 1928 to 1933) (Figure 5).

Reports from many countries, ${ }^{12,18-20}$ including the $\mathrm{UK},{ }^{21}$ indicate that the highest levels of scabies are found during the autumn and winter. In one study, scabies was found to be seasonal only during an epidemic, but not when the prevalence of scabies was low. ${ }^{22}$ The present study shows that seasonality occurs under both sets of circumstances.

The seasonality of scabies may partly be due to the biological characteristics of mites, as a similar seasonality is seen in animal scabies. ${ }^{23}$ Mites survive longer away from the body in cool weather. In addition, high 'mite fertility counts' (based on the number of eggs per burrow) are found in cold weather. ${ }^{24}$

Seasonal changes in human behaviour are important too. Cold weather encourages overcrowding, and other diseases

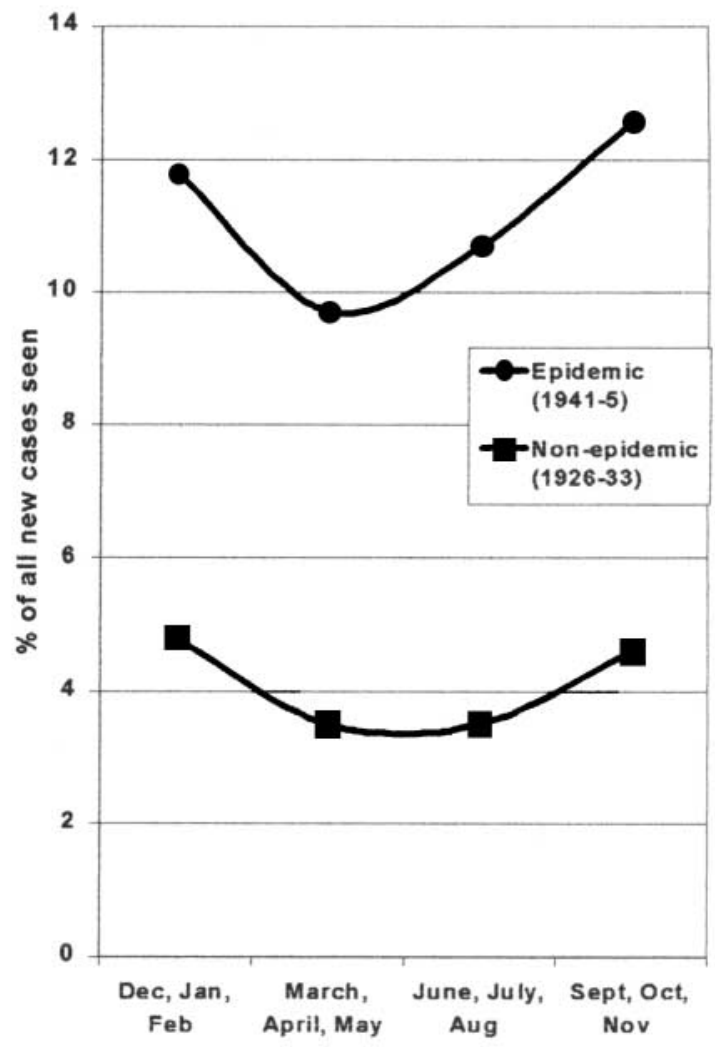

Figure 5 Seasonality of scabies seen at the Royal Infirmary of Edinburgh: epidemic versus non-epidemic years

that are spread by personal contact, such as mumps, ${ }^{25}$ also reach their highest levels in the winter.

In a first attack of scabies, itching does not appear for several weeks. These infestations, therefore, will have been acquired at least one month before any doctor was consulted. As the peak month for scabies at the RIE skin clinic between 1908 and 1969 was January, the peak months for picking it up may have been November or December.

\section{Edinburgh Dispensary for Diseases of the Skin}

The data from 1896 to 1963 are shown in Figure 2. They mirror those from the RIE.

Table 2 Number of children with scabies seen at the Skin Clinic for Edinburgh School Children

\begin{tabular}{ll} 
Year & No. of children with scabies \\
\hline 1938 & 509 \\
1939 & 580 \\
1940 & 868
\end{tabular}




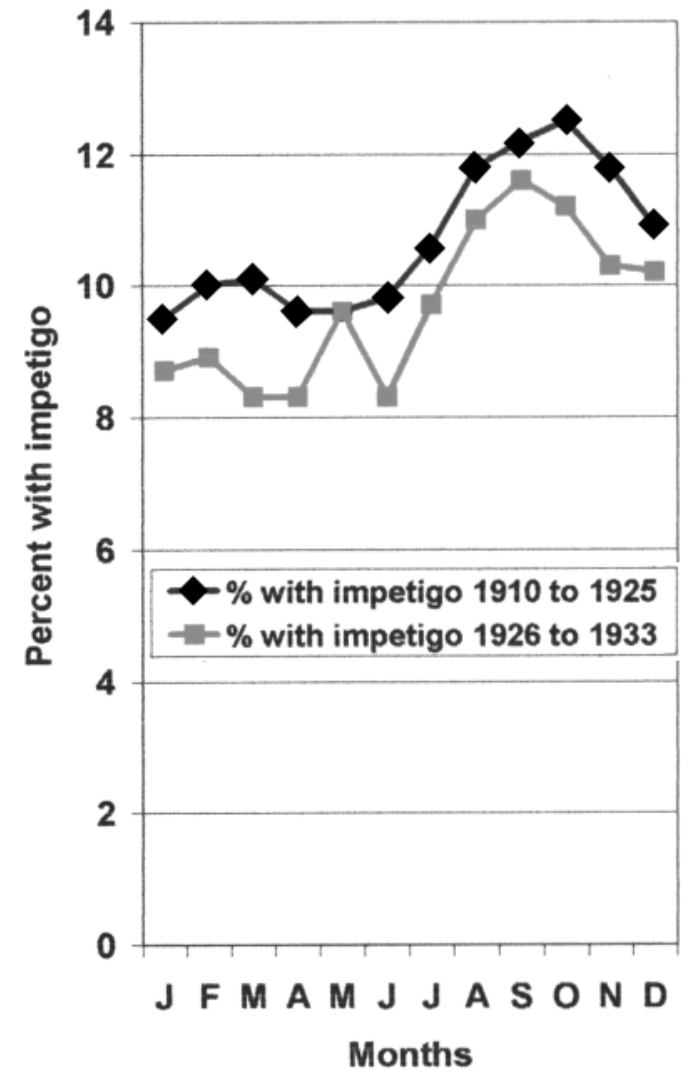

Figure $6 \mathbf{7 4 6 6}$ patients with impetigo: monthly figures showing the percentage of new patients having impetigo (Royal Infirmary of Edinburgh)

\section{Skin Clinic for Edinburgh School Children}

The number of children attending with scabies increased sharply at the onset of the Second World War (see Table 2). From 1938 to 1940 the numbers rose by $70 \%$ - a figure close to the $66 \%$ rise in scabies patients of all ages seen at the RIE over the same period. A similar rise was seen in school clinics in Glasgow. ${ }^{26}$

\section{Other infective skin disorders}

\section{Impetigo}

Over the years patients with impetigo made up a smaller proportion of the new patients seen at the RIE than at the EDDS, which dealt with poorer patients. There were other differences too. Only at the EDDS was there a sharp rise at the time of the First World War, and the fall in cases in the 1940s took place later there. Seasonality was obvious, with peak levels in the late summer and autumn (Figure 6).

Scabies has a 'common alliance' with pyogenic cocci. It breaks down the integrity of the skin and initiates septic complications. However, at the Edinburgh skin clinics, impetigo and scabies have not run parallel courses over the though its decline at the EDDS after the Second World War followed closely on that of scabies. Impetigo favours the summer and autumn, and scabies the winter.

\section{Scalp lice}

The prevalence of scalp lice in Edinburgh schoolchildren was $3.8 \%$ in 1931 and $4.1 \%$ in 1938 , before rising sharply to $18.7 \%$ in $1939 / 1940 .{ }^{27}$ However, no obvious increase in pediculosis capitis was seen at the RIE or the EDDS during the First World War. More cases were seen in September than in any other month.

\section{Tinea capitis}

No clear-cut rise was seen at either the RIE or EDDS at the time of the First World War. The percentage of new patients with tinea capitis was higher at the EDDS before 1913, and at the RIE thereafter. By the 1930s, tinea capitis had become much less common at both clinics.

In 1906, the Medical Officer in charge of the EDDS had wanted to have an X-ray apparatus to treat children with tinea capitis and favus, but at $£ 75$ his proposal was turned down as too expensive. Things were different at the RIE. In 1912 a special school was set up under its control for the education and treatment of these children. ${ }^{1}$ After 1913 the RIE took on the lion's share of these patients. Between 1912 and 1930, far more cases of tinea capitis in Edinburgh were recognized in September, at the start of the school term, than at any other time of the year. ${ }^{28}$

\section{DISCUSSION}

Clinic studies do not measure the prevalence of disease in the community, since they include only those who seek medical help. They can, however, detect swings in prevalence, as shown here by the way that peaks for scabies occurred at the same time in two unconnected Edinburgh skin clinics. Clinic studies also carry the advantage of an accurate diagnosis: in scabies, dermatologists make fewer diagnostic mistakes than those running population or general practice surveys, where errors occur in up to $25 \%$ of cases. ${ }^{29}$

This study shows that scabies differed in many ways from the other skin infections and infestations seen in Edinburgh during the twentieth century. Both of its major epidemics coincided with a World War. The complex causes of these were centred on the social unrest and population movements that accompany war, but more subtle factors were at work too, including the everchanging seasons and, perhaps, the arrival of new generations of susceptible individuals.

Several sources of information have been used in this study, each providing a different piece of the overall 'health jigsaw'. The pattern of skin disease in Edinburgh in the early part of the twentieth century was similar to that found 
recently in developing countries. ${ }^{30}$ The public health measures in place in Edinburgh at that time were poor; but as living conditions and public health measures improved, skin infections and infestations steadily faded from the scene. This began long before antibiotics and immunization arrived, and is currently being repeated worldwide in developing countries. Nevertheless, scabies will undoubtedly survive and pounce again. That is the lesson of history.

\section{REFERENCES}

1 Percival GH. Some Aspects of the Development of Dermatology with Special Reference to the Contribution of the Edinburgh School [Thesis]. Edinburgh: Library of the Department of Dermatology, University of Edinburgh, 1982:289

2 Savin JA. Dermatology in Edinburgh: the first 100 years. BMJ 1984;289:1762-4

3 Walker N. A review of 16 months work in the skin department of the Royal Infirmary, Edinburgh. Scot Med Surg J 1908;22:517-26

4 Benton EC, Hunter JAA. The dermatology out-patient service: a study of out-patient referrals in a Scottish population. Br J Dermatol 1984;110:195-201

5 McKenna DB, Shepherd S, Russell S, Benton EC. Dermatology outpatient workload in the South-East of Scotland, 1981-2000. Br J Dermatol 2001;(suppl 59):74

6 Harris DWS, Benton EC, Hunter JAA. The changing face of outpatient referrals in the south-east of Scotland. Br J Dermatol 1990; 123:745-50

7 Reports of Diseases treated at the Edinburgh New Town Dispensary 1815 to 1819. Edinb Med Surg J 1816;12:245-9, 375-8. 1817;13:11724, 245-6, 398-9, 521-2. 1818;14:120-6, 256-60, 389-401, 6534. $1819 ; 15: 309-16,474-6$

8 Percival GH. Organized treatment for scabies. Br J Dermatol 1941;53:346-50

9 Keir D, ed. The City of Edinburgh (The Third Statistical Account). Glasgow: Collins, 1966:338-41

10 Hirsch A. Handbook of Geographical and Historical Pathology, Vol. 2. London: New Sydenham Society, 1885:360
11 Friedman R. The Story of Scabies, Vol. 1. New York: Froben Press, 1947:86-7

12 Christophersen RD. The epidemiology of scabies in Denmark 1900 to 1975. Arch Dermatol 1978;114:747-50

13 Burkhart CG. Scabies: an epidemiological reassessment. Ann Intern Med 1983;98:498-503

14 Catterall RD. Biological effects of sexual freedom. Lancet 1981;i:315-19

15 Knowles FC. Scabies in military and civil life. JAMA 1918;71:1657-8

16 McLaren R. Effects of war on the incidence of scabies. Lancet 1920;i:566

17 Gray AMH. Discussion on prevention and treatment of parasitic diseases. Br J Dermatol 1941;53:145-60

18 Ahmed S, Aftabuddin AK. Common skin diseases (analysis of 7636 cases). Bangladesh Med Res Counc Bull 1977;3:41-5

19 Thieberge G. Sur les variations de fréquence de la gale. Bull Acad Méd Paris 1922;88:52

20 Tuzun Y, Kotogyan A, Cenesizoglu E, et al. The epidemiology of scabies in Turkey. Int J Dermatol 1980;19:41-4

21 Downs ARM, Harvey I, Kennedy CTC. The epidemiology of head lice and scabies in the UK. Epidemiol Infection 1999;122:471-7

22 Kimchi N, Green MS, Stone D. Epidemiologic characteristics of scabies in the Israel Defence Force. Int J Dermatol 1989;28:180-2

23 Tikaram SM, Ruprah NS. Incidence of sarcoptic mange in buffaloes in India. Trop Anim Health Prod 1886;18:86-90

24 Sokolova TV, Radchenko MI, Lange AB. The seasonability of scabies morbidity and the fertility of the itch mite Sarcoptes scabei de Geer as an index of the activity of a population of the causative agent. Vestn Dermatol Venereol 1989;11:12-15

25 Lilienfield AM, Lilienfield DE. Foundations of Epidemiology, 2nd edn. Oxford: Oxford University Press, 1980:166-7

26 Wilson TS. A study of the incidence of scabies in Glasgow from the early 1920s. Med Officer 1969;122:125-7

27 Tait HP. A Doctor and Two Policemen: the History of the Edinburgh Health Department 1862-1974. Edinburgh: Edinburgh District Council, Environmental Health Department, 1974:97-8

28 Percival GH. A note on the epidemiology of tinea capitis. BMJ 1932;i:93-4

29 Mellanby K. Scabies. London: Oxford University Press, 1943:65

30 Verhagen ARHB, Koten JW, Chaddah VK, Patel RI. Skin diseases in Kenya. Arch Dermatol 1968;98:577-85 